\title{
Disc Brake Vibration Model Based on Stribeck Effect and Its Characteristics under Different Braking Conditions
}

\author{
Shugen Hu and Yucheng Liu \\ College of Mechanical Engineering, Zhejiang University, Hangzhou 310027, China \\ Correspondence should be addressed to Shugen Hu; hsgdj@zju.edu.cn
}

Received 9 March 2017; Revised 17 April 2017; Accepted 23 April 2017; Published 28 May 2017

Academic Editor: Oleg V. Gendelman

Copyright (C) 2017 Shugen Hu and Yucheng Liu. This is an open access article distributed under the Creative Commons Attribution License, which permits unrestricted use, distribution, and reproduction in any medium, provided the original work is properly cited.

A 7-degree-of-freedom (DOF) vibration model of a fixed-caliper disc brake system was developed herein based on the Stribeck effect. Furthermore, a dynamometer brake test was conducted to determine the characteristic system parameters of the 7-DOF vibration model. This model was developed to study the effects of braking conditions, such as disc rotational speed and brake pressure on brake noise. The complex eigenvalues of the system were also calculated to analyze the brake model stability under different braking conditions. The acceleration time history diagrams and phase plots were obtained by solving the equations of the system. The numerical calculation results showed that the brake noise increased with an increasing braking force and a decreasing breaking speed. These numerical findings were verified by the results of the dynamometer tests.

\section{Introduction}

Fixed-caliper disc brakes are widely used in passenger and light commercial vehicles. One or more pairs of opposing pistons are used in such brake systems to clamp both sides of the disc, with the caliper carrying the pistons fixed on a knuckle, such that its position does not change relative to the disc. However, with the increasing demand for driving comfort, a greater need to address the noise, vibration, and harshness (NVH) issues of such brake systems is required. Brake noise, especially "brake squeal," which occurs with frequencies of $1-16 \mathrm{kHz}$ and reaches the upper human auditory threshold, is of particular importance in current vehicle NVH engineering [1-3].

Studies on brake noise began in the 1930s [4] when researchers conducted diverse investigations from different perspectives, including frictional properties of utilized materials and structures of the brake system parts $[5,6]$. These studies revealed a close relationship between brake noise and vibrational excitation caused by friction between the disc and the lining $[7,8]$. The theory of this relationship is based on the two following basic characteristics of friction coefficients: (1) the static friction coefficient is higher than the sliding friction coefficient and (2) the friction coefficients decrease with the increasing relative velocity within a certain range. The former characteristic produces the system stick-slip effect, which causes vibration [9]. Meanwhile, the latter induces negative damping, which results in system instability [10-12]. However, previous studies on brake noise that investigated the friction characteristics mainly considered the self-excited vibration at a specific friction coefficient or unstable vibration caused by the negative slope in the relative velocity versus the friction coefficient curve [13-15].

Accordingly, 2-DOF vibration models were employed in most of the previous studies, in which brake squeal was examined based on friction. This made it difficult to simulate the working conditions during braking, thereby hindering the investigation of the interaction between the different parts of the brake assembly [16-18]. Vibration models with more than two DOFs have consequently been developed for the brake squeal investigation. For example, Kinkaid designed a 4-DOF brake model that captured some of the dynamics of a set of brake pads used to stop a rotor [19]. Ahmed built a 10-DOF mathematical prediction model to investigate the effects of different brake component parameters on a ventilated disc brake squeal [20]. Wang et al. developed a 


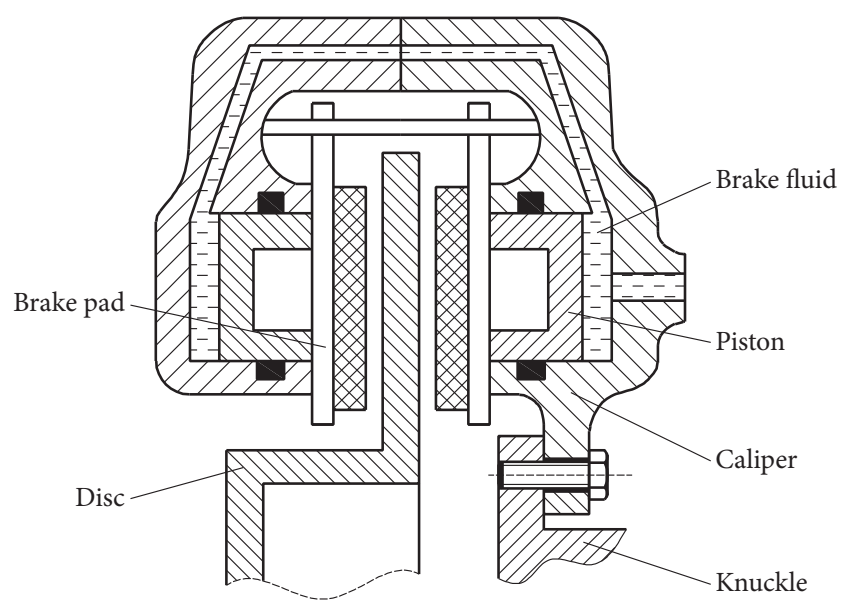

FIGURE 1: Structure of a fixed-caliper disc brake.

4-DOF model of a disc brake with friction and contact loss nonlinearities to investigate the mechanism and the dynamic characteristics of a brake squeal [21]. The present study developed a 7-DOF vibration model of a fixed-caliper brake system based on the Stribeck effect. A dynamometer test was conducted to determine the characteristic system parameters. Furthermore, the effects of the braking conditions on the system stability were studied.

\section{Establishment of the Brake Vibration System}

2.1. Establishment of the State Equations. Figure 1 shows a typical structure of a fixed-caliper disc brake for a vehicle. During the braking process, the brake fluid pressure increases, and the rotating disc is clamped by both sides of the brake linings, thereby resulting in the deceleration of the moving vehicle. The vibration model of the brake system, which basically comprises the caliper, disc, and both sides of the brake linings, can be simplified as shown in Figure 2.

In Figure 2, $m_{d}$ is the mass of the disc; $m_{c}$ is the mass of the caliper; $m_{1}$ and $m_{2}$ are the masses of the inner and outer brake linings, respectively; $v_{0}$ is the absolute linear velocity of the brake disc assumed to be in the $y+$ direction; and $F$ is the brake pressure on either lining of both sides, considering that the inner and outer pistons are of the same size. The movement along the $x$-axis was considered for the disc, while simultaneous movements along the $x$ - and $y$ axes were considered for the caliper and both brake linings. Suppose that the disc moves in the $x+$ direction during the braking process, the inner lining would move in an $x-/ y+$ direction; the outer lining would move in an $x+/ y+$ direction; and the caliper would move in an $x+/ y+$ direction. This hypothesis was used to define the initial state of the system to facilitate analysis, such that the directions of the reaction forces on the springs and dampers can be obtained. The final results would not be affected by these assumptions because the obtained values of the reaction forces would be negative if their directions are opposite the assumed direction.

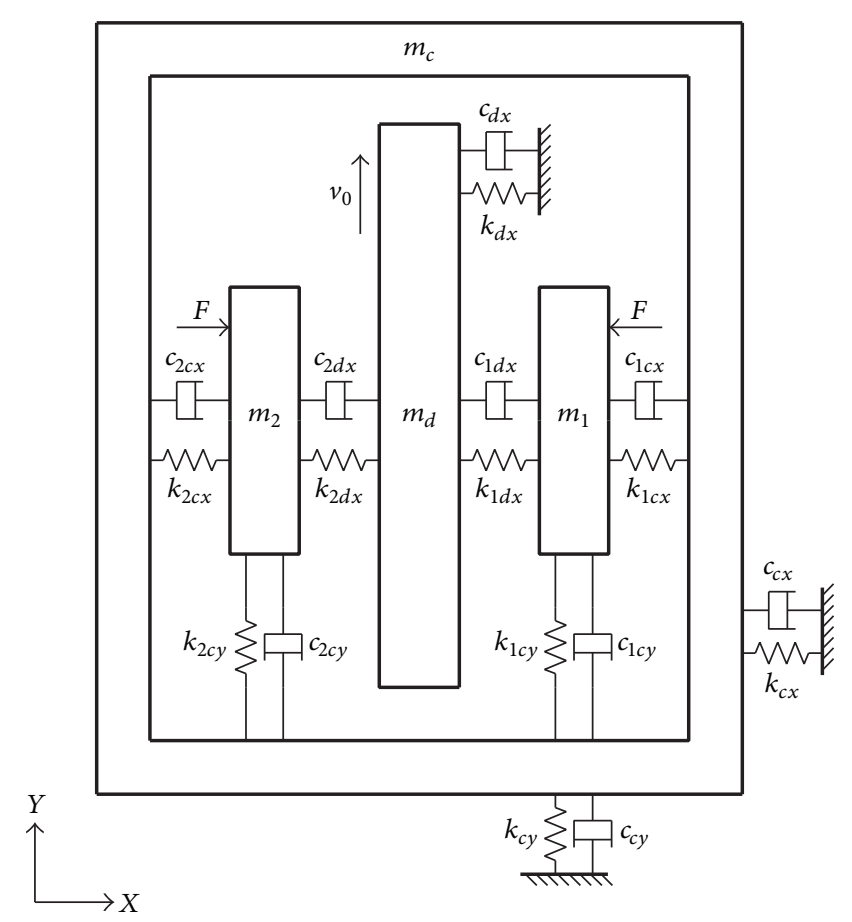

FIgURE 2: Vibration model of a fixed-caliper disc brake.

Based on the abovementioned assumptions and the relationships among the different parts in the brake system, the equations of the vibration system shown in Figure 2 can be obtained as follows by using Newton's law:

$$
\begin{aligned}
m_{c} \ddot{x}_{c}= & -c_{c x} \dot{x}_{c}+c_{2 c x}\left(\dot{x}_{2}-\dot{x}_{c}\right)-c_{1 c x}\left(\dot{x}_{c}-\dot{x}_{1}\right)-k_{c x} x_{c} \\
& +k_{2 c x}\left(x_{2}-x_{c}\right)-k_{1 c x}\left(x_{c}-x_{1}\right), \\
m_{c} \ddot{y}_{c}= & -c_{c y} \dot{y}_{c}+c_{2 c y}\left(\dot{y}_{2}-\dot{y}_{c}\right)+c_{1 c y}\left(\dot{y}_{1}-\dot{y}_{c}\right)-k_{c y} y_{c} \\
& +k_{2 c y}\left(y_{2}-y_{c}\right)+k_{1 c y}\left(y_{1}-y_{c}\right), \\
m_{d} \ddot{x}_{d}= & -c_{d} \dot{x}_{d}+c_{2 d x}\left(\dot{x}_{2}-\dot{x}_{d}\right)-c_{1 d x}\left(\dot{x}_{1}-\dot{x}_{d}\right) \\
& -k_{d} x_{d}+k_{2 d x}\left(x_{2}-x_{d}\right)-k_{1 d x}\left(x_{d}-x_{1}\right), \\
m_{1} \ddot{x}_{1}= & -F+c_{1 d x}\left(\dot{x}_{d}-\dot{x}_{1}\right)+c_{1 c x}\left(\dot{x}_{c}-\dot{x}_{1}\right) \\
& +k_{1 d x}\left(x_{d}-x_{1}\right)+k_{1 c x}\left(x_{c}-x_{1}\right), \\
m_{1} \ddot{y}_{1}= & F_{f 1}-c_{1 c y}\left(\dot{y}_{1}-\dot{y}_{c}\right)-k_{1 c y}\left(y_{1}-y_{c}\right), \\
m_{2} \ddot{x}_{2}= & F-c_{2 d x}\left(\dot{x}_{2}-\dot{x}_{d}\right)-c_{2 c x}\left(\dot{x}_{2}-\dot{x}_{c}\right) \\
& -k_{2 d x}\left(x_{2}-x_{d}\right)-k_{2 c x}\left(x_{2}-x_{c}\right), \\
m_{2} \ddot{y}_{2}= & F_{f 2}-c_{2 c y}\left(\dot{y}_{2}-\dot{y}_{c}\right)-k_{2 c y}\left(y_{2}-y_{c}\right),
\end{aligned}
$$

where $F_{f 1}$ and $F_{f 2}$ are the frictional forces between the disc and the two brake linings, respectively. The expressions of which were obtained using a Stribeck model and the dynamometer test results (Section 2.2 for a detailed description). Considering the structural symmetry of a fixed-caliper disc brake system, it was assumed that $c_{1}=c_{1 d x}=c_{2 d x}$, 
$k_{1}=k_{1 d x}=k_{2 d x}, c_{2}=c_{1 c y}=c_{2 c y}, k_{2}=k_{1 c y}=k_{2 c y}$, $c_{3}=c_{1 c x}=c_{2 c x}, k_{3}=k_{1 c x}=k_{2 c x}, c_{4}=c_{d x}, k_{4}=k_{d x}$, $c_{5}=c_{c x}, k_{5}=k_{c x}, c_{6}=c_{c y}$, and $k_{6}=k_{c y}$. Furthermore, the generalized displacement $q$ and the generalized velocity $\dot{q}$ were introduced by defining $y_{1}=q_{1}, y_{2}=q_{2}, y_{c}=q_{3}$, $x_{1}=q_{4}, x_{2}=q_{5}, x_{c}=q_{6}$, and $x_{d}=q_{7}$. Thus, the vibration equations could be derived based on generalized coordinates.
Finally, the state variable $z$ was used to rewrite the equations as follows:

$$
\begin{aligned}
z_{i} & =q_{i}, \quad i=1,2, \ldots, 7, \\
z_{i+7} & =\dot{q}_{i}, \quad i=1,2, \ldots, 7 .
\end{aligned}
$$

The system state equations were also obtained as follows:

$$
\begin{aligned}
& \dot{z}_{1}=z_{i+7} \quad(i=1,2, \ldots, 7), \\
& \dot{z}_{8}=\frac{\left[F_{f 1}-c_{2}\left(z_{8}-z_{10}\right)-k_{2}\left(z_{1}-z_{3}\right)\right]}{m_{1}}, \\
& \dot{z}_{9}=\frac{\left[F_{f 2}-c_{2}\left(z_{9}-z_{10}\right)-k_{2}\left(z_{2}-z_{3}\right)\right]}{m_{2}}, \\
& \dot{z}_{10}=\frac{\left[-c_{6} z_{10}+c_{2}\left(z_{9}-z_{10}\right)-k_{6} z_{3}+k_{2}\left(z_{1}+z_{2}-2 z_{3}\right)\right]}{m_{c}}, \\
& \dot{z}_{11}=\frac{\left[-F+c_{1}\left(z_{11}-z_{14}\right)-c_{3}\left(z_{13}-z_{11}\right)+k_{1}\left(z_{7}-z_{4}\right)+k_{3}\left(z_{6}-z_{4}\right)\right]}{m_{1}}, \\
& \dot{z}_{12}=\frac{\left[F-c_{1}\left(z_{12}-z_{14}\right)-c_{3}\left(z_{12}-z_{13}\right)-k_{1}\left(z_{5}-z_{7}\right)-k_{3}\left(z_{5}-z_{6}\right)\right]}{m_{2}}, \\
& \dot{z}_{13}=\frac{\left[-c_{5} z_{13}+c_{3}\left(z_{11}+z_{12}-2 z_{13}\right)-k_{5} z_{6}+k_{3}\left(z_{4}+z_{5}-2 z_{6}\right)\right]}{m_{c}}, \\
& \dot{z}_{14}=\frac{\left[-c_{4} z_{14}+c_{1}\left(z_{11}+z_{12}-2 z_{14}\right)-k_{4} z_{7}+k_{1}\left(z_{4}+z_{5}-2 z_{7}\right)\right]}{m_{d}} .
\end{aligned}
$$

2.2. Representation of the Braking Force Based on the Stribeck Effect. In 1903, Stribeck found that the Coulomb friction model could not be used to properly describe the actual friction behavior, especially the relationship between the friction coefficient and the normal pressure [22]. The relative velocity in the classic Coulomb friction model was not considered in the sliding friction. The transition between the static friction and the sliding friction was discrete. Furthermore, the value of the sliding friction coefficient was always smaller than the maximum static friction coefficient. However, Stribeck proposed that the sliding friction coefficient decreased with the increasing relative velocity and presented the former as a continuous function of the latter for low velocities. The friction behavior in the low-velocity region was referred to as the negative-slope friction phenomenon because of the negative slope of the velocity-friction curve. The following exponential model of the phenomenon was proposed by Bo and Pavelescu [23]:

$$
f(v)=f_{c}+\left(f_{s}-f_{c}\right) e^{-\left(v / v_{s}\right)^{\delta}}
$$

where $f_{c}$ is the Coulomb friction force; $v$ is the relative velocity between the two contacting surfaces; $v_{s}$ is the Stribeck velocity; and $v_{s}$ and $\delta$ are the empirical constants. Bo and Pavelescu proposed a range of $0.5-1$ for $\delta$ [23], while some other scholars considered $\delta=1$ or $\delta=2$ as reasonable $[24,25]$. The frictional force was directly related to the normal pressure. Therefore, (4) can be rewritten as follows:

$$
\begin{aligned}
& f(v)=F \cdot \mu(v), \\
& \mu(v)=\mu_{c}+\Delta \mu \cdot e^{-\left(v / v_{s}\right)^{\delta}} .
\end{aligned}
$$

The friction conditions of the brake linings on both sides were similar because of the structural symmetry of the fixedcaliper brake. Hence, $F_{f 1}$ and $F_{f 2}$ can be expressed as follows by substituting the variables of the state equations into (5) and (6) and setting $\delta=1$ :

$$
\begin{aligned}
F_{f 1}= & \operatorname{sgn}\left(v_{0}-\frac{60 z_{8}}{2 \pi R_{E}}\right) \cdot F \\
& \cdot\left[\mu_{c}+\Delta \mu \cdot \exp \left(-\frac{\left|v_{0}-\left(60 z_{8} / 2 \pi R_{E}\right)\right|}{v_{s}}\right)\right], \\
F_{f 2}= & \operatorname{sgn}\left(v_{0}-\frac{60 z_{9}}{2 \pi R_{E}}\right) \cdot F \\
& \cdot\left[\mu_{c}+\Delta \mu \cdot \exp \left(-\frac{\left|v_{0}-\left(60 z_{9} / 2 \pi R_{E}\right)\right|}{v_{s}}\right)\right] .
\end{aligned}
$$


TABLE 1: Parameters determined by fitting of the Stribeck friction model.

\begin{tabular}{lcc}
\hline Parameter & Value & Standard error \\
\hline$\mu_{c}$ & 0.27090 & 0.00278 \\
$\Delta \mu$ & 0.14479 & 0.00230 \\
$\nu_{s}$ & 257.75876 & 10.03653 \\
\hline
\end{tabular}

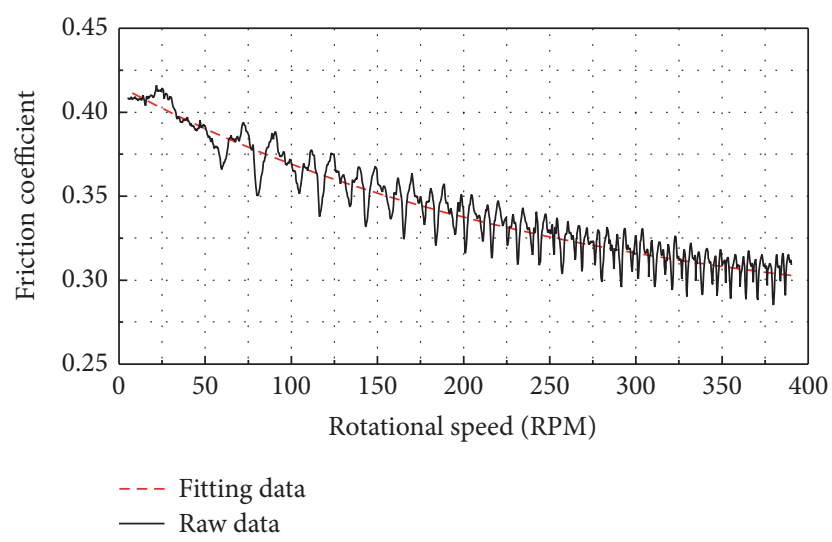

FIGURE 3: $n-\mu$ curve fitted using the dynamometer test results.

The friction forces between the disc and the inner/outer brake linings in the vibration system presented as (7) were based on the Stribeck friction model, where sgn is the sign function used to determine the direction of the friction on the contacting surfaces; $z_{8}$ and $z_{9}$ are the linear velocities of the contacting surfaces in $\mathrm{m} / \mathrm{s}$ (a unit conversion factor is required because $v_{0}$ is the rotational speed of the disc in RPM); and $R_{E}$ is the effective radius of the brake system. The values of $\mu_{c}, \Delta \mu, v_{s}$, and $R_{E}$ were required for calculation using the abovementioned equations. $R_{E}$ is a design parameter with a value of $0.018 \mathrm{~m}$ and provided by the vehicle manufacturer. The values of the other parameters can be determined by the dynamometer test results.

The tests in the present study were conducted using a model 3900 brake NVH dynamometer (manufactured by LINK Engineering Company) and based on the SAE J2521 (Ver. 2013 Apr) test procedure. Hence, the dynamic characteristics of the break friction coefficient during the entire braking process from $50 \mathrm{~km} / \mathrm{h}$ to rest can be determined. Figure 3 presents the obtained raw data. The curve obviously matched well the characteristics of the Stribeck effect although some fluctuations in the friction, which were caused by creeping, existed. All 1412 sets of friction coefficient and rotational speed data were substituted into (4) and (6) by fitting the raw data shown in Figure 3. The values of $\mu_{c}, \Delta \mu$, and $v_{s}$ can then be determined. Table 1 and Figure 3 show the obtained parameter values and the fitted curve, respectively.

\section{Numerical Calculations}

3.1. Determination of the System Stability Using the ComplexEigenvalue Method. A point at which $\{\dot{z}\} \neq\{0\}$ is referred to as an ordinary point in the state space, while one that satisfies (8) is referred to as a balance point.

$$
\{\dot{z}\}=\left\{\dot{z}_{1}, \dot{z}_{2}, \ldots, \dot{z}_{14}\right\}^{T}=\left\{Z_{i}\left(z_{1}, z_{2}, \ldots, z_{14}\right)\right\}=\{0\}
$$

The coordinates of a balance point should be calculated to determine the stability. The change rates $\dot{z}_{i}(i=1,2, \ldots, 14)$ of all the state variables should be 0 at a balance point. Hence, the coordinates can be calculated as follows by substituting (8) into the system state equations:

$$
\begin{aligned}
& z_{1 e}=z_{2 e}=F_{f 0}\left(\frac{2}{k_{6}}+\frac{1}{k_{2}}\right), \\
& z_{3 e}=\frac{2 F_{f 0}}{k_{6}} \\
& z_{4 e}=\frac{-F}{\left(k_{1}+k_{3}\right)}, \\
& z_{5 e}=\frac{F}{\left(k_{1}+k_{3}\right)}, \\
& z_{m e}=0, \quad m=6,7, \ldots, 14, \\
& F_{f 0}=F \cdot\left(\mu_{c}+\Delta \mu \cdot e^{-v_{0} / v_{s}}\right) .
\end{aligned}
$$

Equation (9) obviously showed that a balance point cannot occur at the origin of the coordinate in this system. Therefore, coordinate transformation was necessary to satisfy the requirements for the system linearization in the process of ascertaining the system stability. McLaughlin's expansion was applied, with items of the second or higher orders ignored, because the functions of $F_{f 1}$ and $F_{f 2}$ were the only nonlinear terms in the system state equations. The approximate expressions of $F_{f 1}$ and $F_{f 2}$ near the origin are presented as follows:

$$
\begin{aligned}
F_{f 1}= & F \cdot\left(\mu_{c}+\Delta \mu \cdot e^{-v_{0} / v_{s}}\right)+F \cdot \Delta \mu \cdot \frac{60}{2 \pi R_{E} v_{s}} \cdot e^{-v_{0} / v_{s}} \\
& \cdot z_{8}, \\
F_{f 1}= & F \cdot\left(\mu_{c}+\Delta \mu \cdot e^{-v_{0} / v_{s}}\right)+F \cdot \Delta \mu \cdot \frac{60}{2 \pi R_{E} v_{s}} \cdot e^{-v_{0} / v_{s}} \\
& \cdot z_{9} .
\end{aligned}
$$

The linearized state equations near the origin can be obtained by substituting (11) into the state equations after coordinate transformation. This can also be used to determine the Jacobian matrix and the equations of the system characteristics shown as (12). The existence of the positive real parts of the eigenvalues is the necessary and sufficient condition for establishing a balance point to be unstable. 
TABLE 2: Vibration model parameters of the fixed-caliper disc brake.

\begin{tabular}{|c|c|c|c|c|c|}
\hline Mass & Value (kg) & Stiffness & Value $\left(\mathrm{N} \cdot \mathrm{m}^{-1}\right)$ & Damping & Value $\left(\mathrm{N} \cdot \mathrm{s} \cdot \mathrm{m}^{-1}\right)$ \\
\hline$m_{1}$ & 0.35 & $k_{1}$ & $1.5 \times 10^{5}$ & $c_{1}$ & 5 \\
\hline$m_{2}$ & 0.35 & $k_{2}$ & $7.5 \times 10^{5}$ & $c_{2}$ & 30 \\
\hline$m_{c}$ & 5.56 & $k_{3}$ & $7.5 \times 10^{5}$ & $c_{3}$ & 15 \\
\hline \multirow[t]{3}{*}{$m_{d}$} & 7.04 & $k_{4}$ & $1.0 \times 10^{6}$ & $c_{4}$ & 40 \\
\hline & & $k_{5}$ & $1.5 \times 10^{6}$ & $c_{5}$ & 50 \\
\hline & & $k_{6}$ & $1.5 \times 10^{6}$ & $c_{6}$ & 50 \\
\hline
\end{tabular}

TABLE 3: Number of eigenvalues with positive real parts.

\begin{tabular}{|c|c|c|c|c|c|c|c|c|c|}
\hline \multirow{2}{*}{ Disc speed (RPM) } & \multicolumn{9}{|c|}{ Brake pressure $(\mathrm{N})$} \\
\hline & 300 & 400 & 500 & 600 & 700 & 800 & 1000 & 1200 & 1500 \\
\hline 15 & 0 & 0 & 2 & 2 & 4 & 4 & 6 & 6 & 6 \\
\hline 25 & 0 & 0 & 2 & 2 & 2 & 4 & 6 & 6 & 6 \\
\hline 42 & 0 & 0 & 0 & 2 & 4 & 4 & 6 & 6 & 6 \\
\hline 83 & 0 & 0 & 0 & 0 & 2 & 2 & 4 & 4 & 6 \\
\hline 100 & 0 & 0 & 0 & 0 & 0 & 2 & 4 & 4 & 6 \\
\hline 150 & 0 & 0 & 0 & 0 & 0 & 0 & 2 & 4 & 4 \\
\hline 200 & 0 & 0 & 0 & 0 & 0 & 0 & 2 & 2 & 4 \\
\hline 250 & 0 & 0 & 0 & 0 & 0 & 0 & 0 & 2 & 2 \\
\hline
\end{tabular}

Hence, the stability of the system balance point can be determined by calculating the eigenvalues of the system.

$$
\begin{aligned}
a_{i, j} & =\left.\frac{\partial Z_{i}\left(z_{1}, z_{2}, \ldots, z_{14}\right)}{\partial z_{j}}\right|_{z_{1}=z_{2}=\cdots=z_{14}=0}, \\
\operatorname{det}([a]-\lambda[1]) & =\left|\begin{array}{cccc}
a_{1,1}-\lambda & a_{1,2} & \cdots & a_{1,14} \\
a_{2,1} & a_{2,2}-\lambda & \ldots & a_{2,14} \\
\vdots & \vdots & \ddots & \vdots \\
a_{14,1} & a_{14,2} & \cdots & a_{14,14}-\lambda
\end{array}\right| \\
& =0 .
\end{aligned}
$$

In the present study, the major working condition parameters of the brake system included the initial disc speed $v_{0}$ and the brake pressure $F$. Different values of these parameters were applied to the system vibration model to numerically ascertain the stability of the balance point under various working conditions. A total of 72 working conditions were considered in the present study based on the actual brake conditions comprising various combinations of brake pressure $F$ value of $300,400,500,600,700,800,1000,1200$, and $1500 \mathrm{~N}$ and initial disc speed $v_{0}$ values of $15,25,42,83,100,150,200$, and $250 \mathrm{RPM}(25,42,83$, and $250 \mathrm{RPM}$ correspond to the linear speeds of $3,5,10$, and $30 \mathrm{~km} / \mathrm{h}$ in SAE J2521, resp.). Table 2 shows the employed values of the other parameters of the vibration system based on the structure symmetry and the connection relationships among the different parts of the brake system.
MATLAB was used to calculate the eigenvalues of the system to qualitatively investigate the stability of the system under different working conditions. Table 3 presents the number of eigenvalues with positive real parts under each working condition.

Several balance points with differing stabilities could be present for a nonlinear vibration system. Accordingly, the stability of a nonlinear system cannot be determined based only on the stability of one balance point. Therefore, McLaughlin's expansion was used to linearize the nonlinear terms, such that the system equations could be linearized and approximately maintained at the balance point. The stability of the vibration system after linearization could be determined based on the stability of the balance point because there can only be one balance point for a liner vibration system.

The stability of the brake vibration system at any rotational speed was closely related to the pressure applied on the brake linings according to the data in Table 3 . The system may become unstable when the brake pressure $F$ reaches a certain threshold. The number of eigenvalues with positive real parts increased with the increase of $F$. In addition, the value of $F$, at which the system became unstable, varied with the rotational speed. This result indicated that the probability of instability of a fixed-caliper disc brake system increased with the increasing brake pressure at a given rotational speed.

Furthermore, the system eigenvalues with positive real parts only occurred when the brake pressure reached the threshold, and the threshold increased with the increasing rotational speed. In other words, the brake system more easily became unstable at a lower vehicle speed. Moreover, a higher brake pressure was required to cause an instability at a higher speed. 

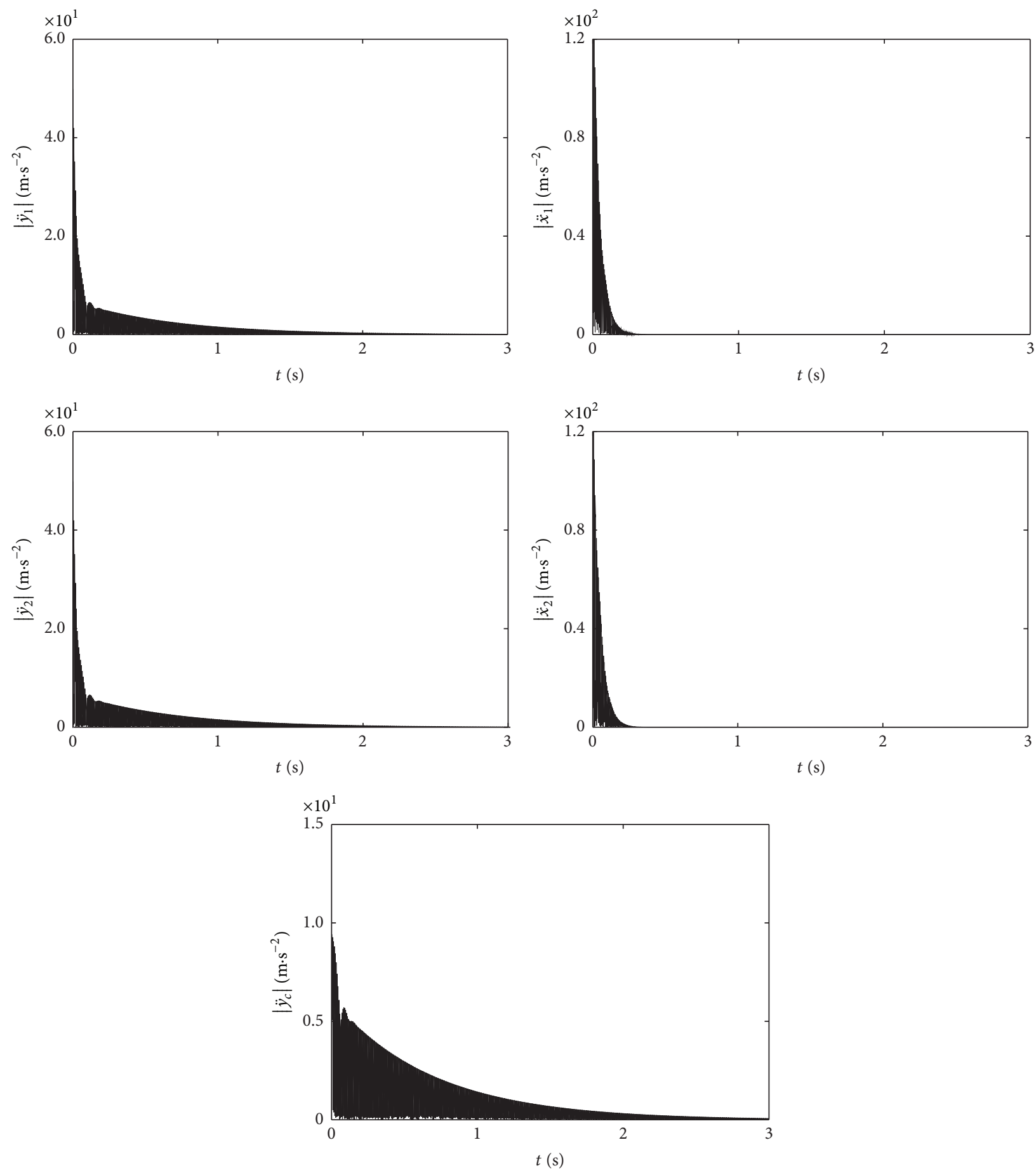

FIGURE 4: System acceleration time history diagrams for $v_{0}=150 \mathrm{RPM}$ and $F=500 \mathrm{~N}$.

3.2. System Time History Diagrams and Phase Plots. The determined equations of the brake system were used to obtain the corresponding acceleration time history diagrams and the phase plots for further analysis of the relationship between the working conditions and the system stability. All 72 working conditions were considered. Three representative working conditions were selected to reflect the influence of the disc rotation speed and the brake pressure on the system stability with the obtained diagrams in Figures 4-9. Seven acceleration time history diagrams and seven phase plots were obtained for each working condition considering the seven DOFs and 14-dimensional phase spaces in the system. The caliper and the disc remained static along the $x$-axis of the vibration system because of the structural symmetry 

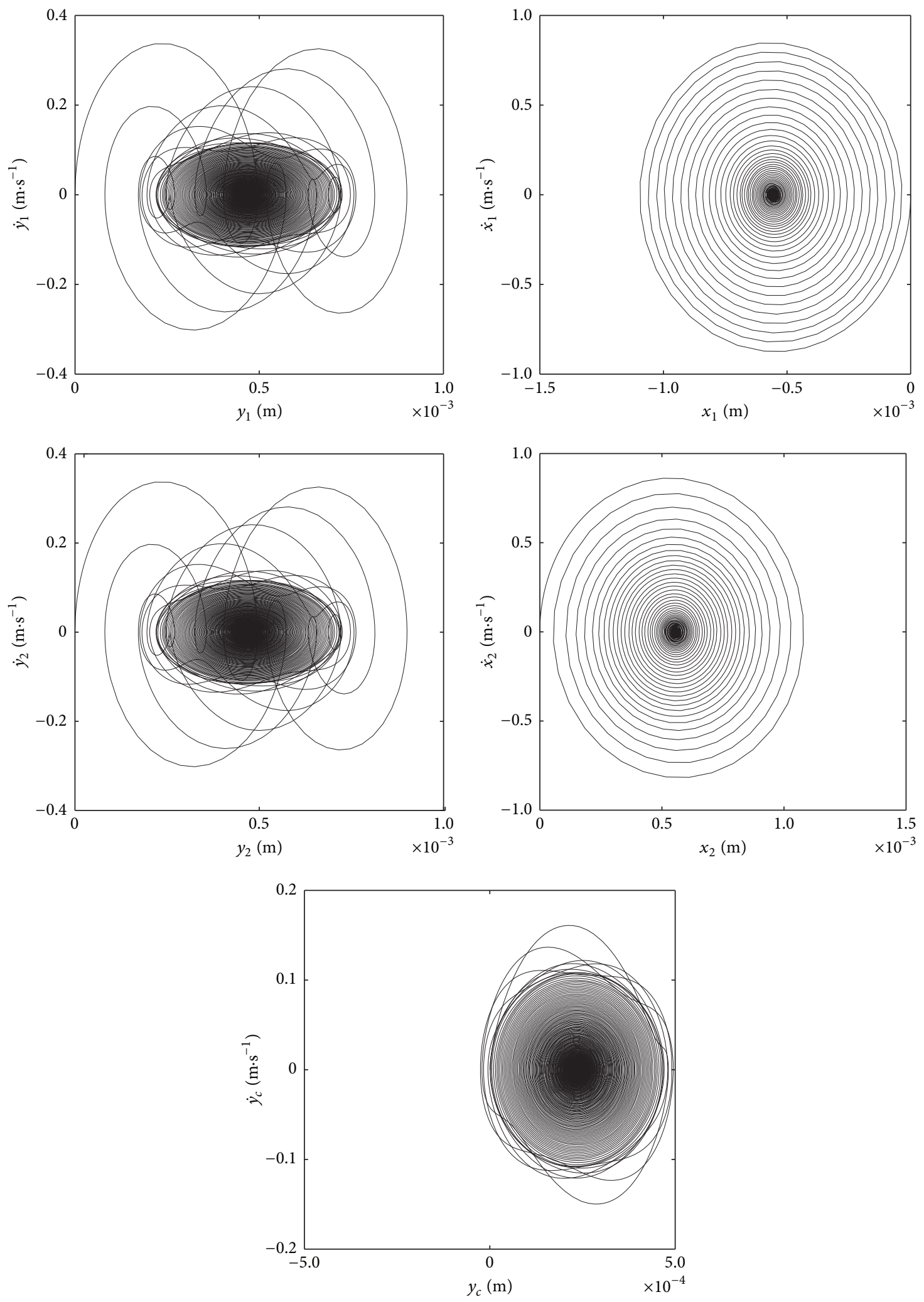

Figure 5: System phase plots for $v_{0}=150 \mathrm{RPM}$ and $F=500 \mathrm{~N}$. 

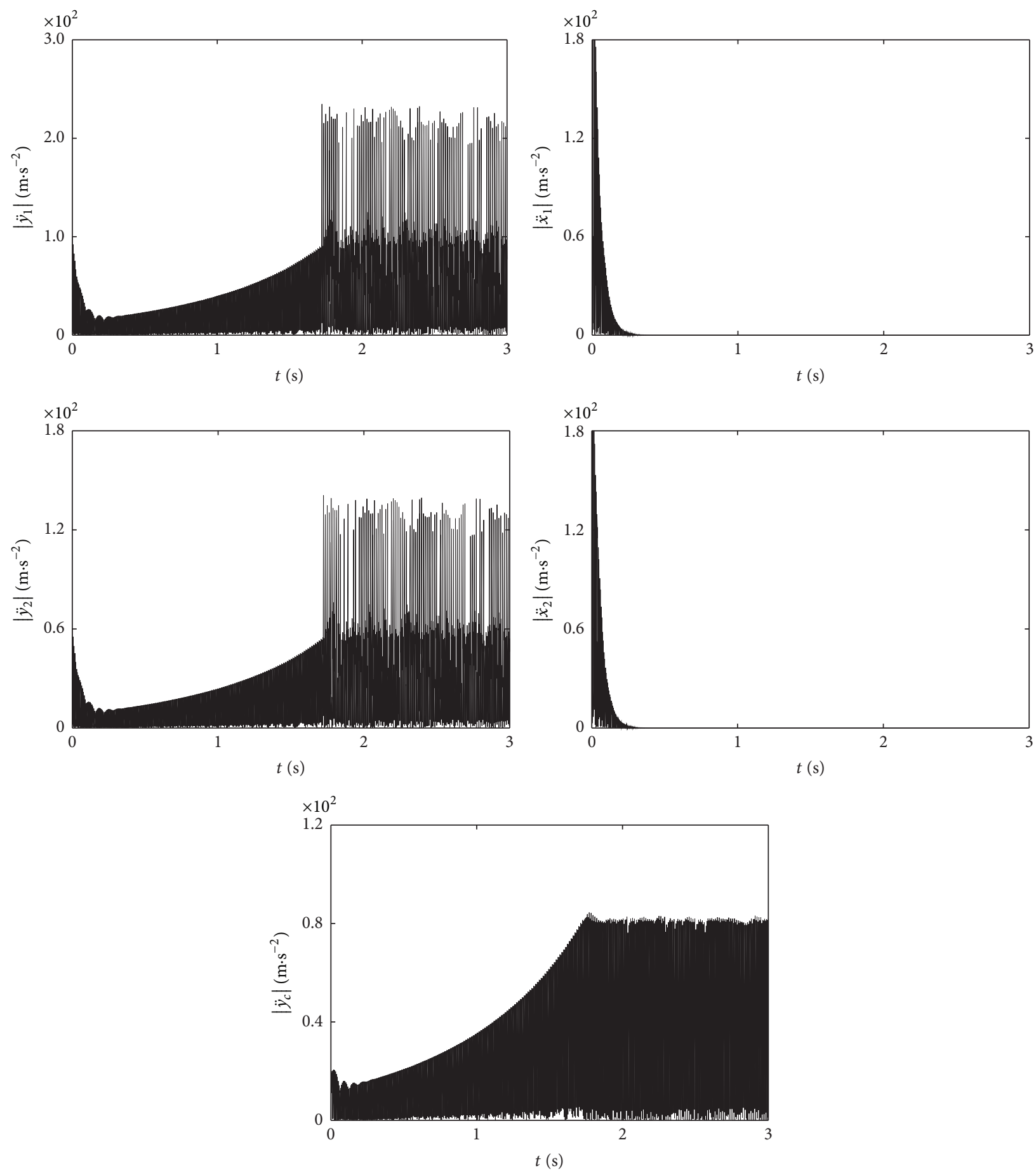

FIGURE 6: System acceleration time history diagrams for $v_{0}=150 \mathrm{RPM}$ and $F=1000 \mathrm{~N}$.

of the fixed-caliper brake system, thereby causing the forces applied on the caliper and the disc along the $x$-axis to always occur in pairs of equal magnitude, but opposing directions. Consequently, the displacement, velocity, and acceleration of $x_{c}$ and $x_{d}$ remained 0 during the braking process, which comprised a horizontal line at 0 in the acceleration time history diagrams and a single dot at the origin in the phase plots. Therefore, $x_{c}$ and $x_{d}$ figures were omitted.
All the unstable DOFs of the vibration system were concentrated on the $y$-axis in each acceleration time history diagram. However, though the vibration on the $x$-axis of the inner and outer linings began after the excitation by the brake pressure $F$, but the amplitude of the acceleration rapidly attenuated and finally reached the steady state.

Figures 4-7 present the effects of the brake pressure on the system vibration characteristics at a given rotational 

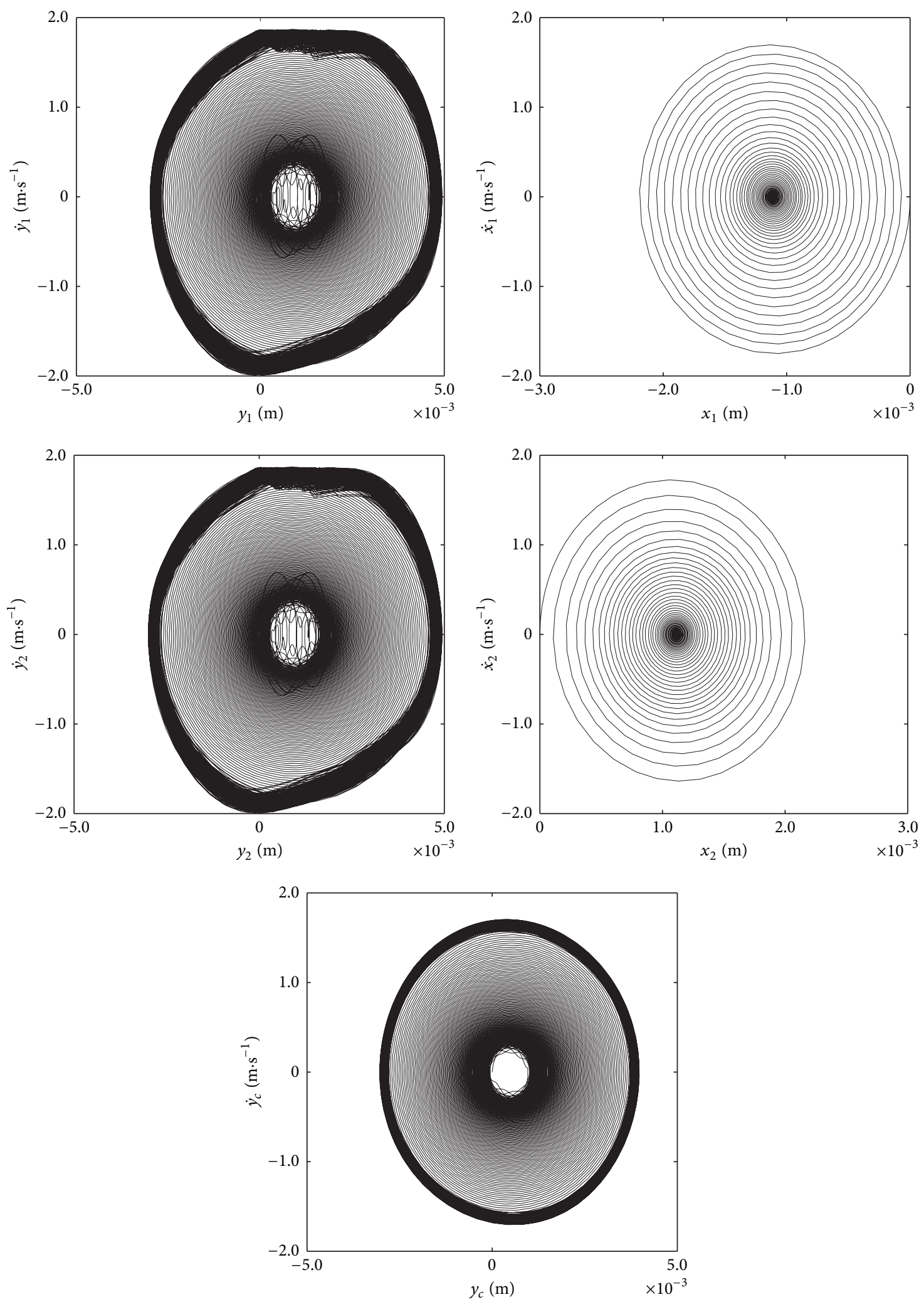

FIGURE 7: System phase plots for $v_{0}=150 \mathrm{RPM}$ and $F=1000 \mathrm{~N}$. 

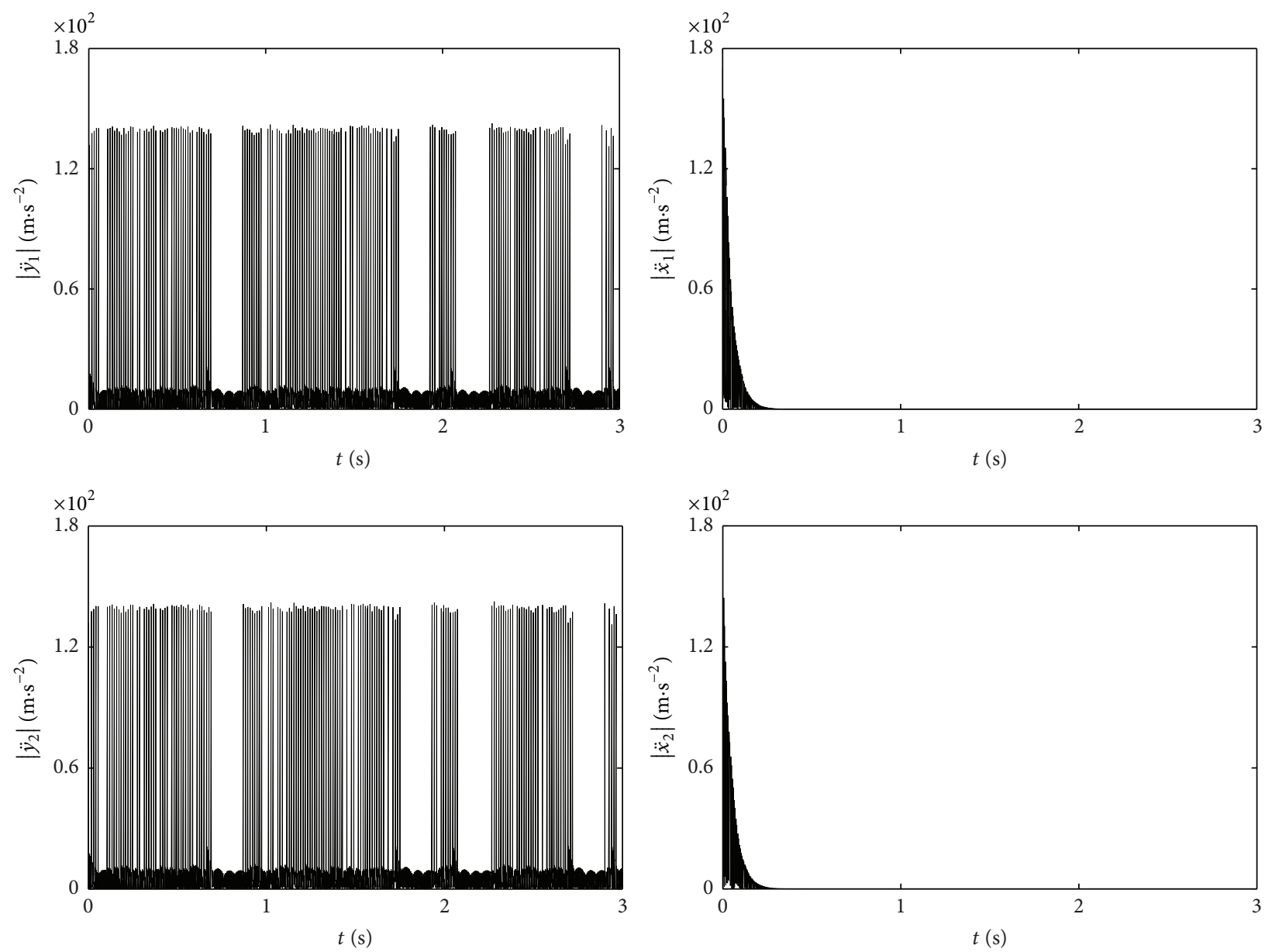

$t$ (s)

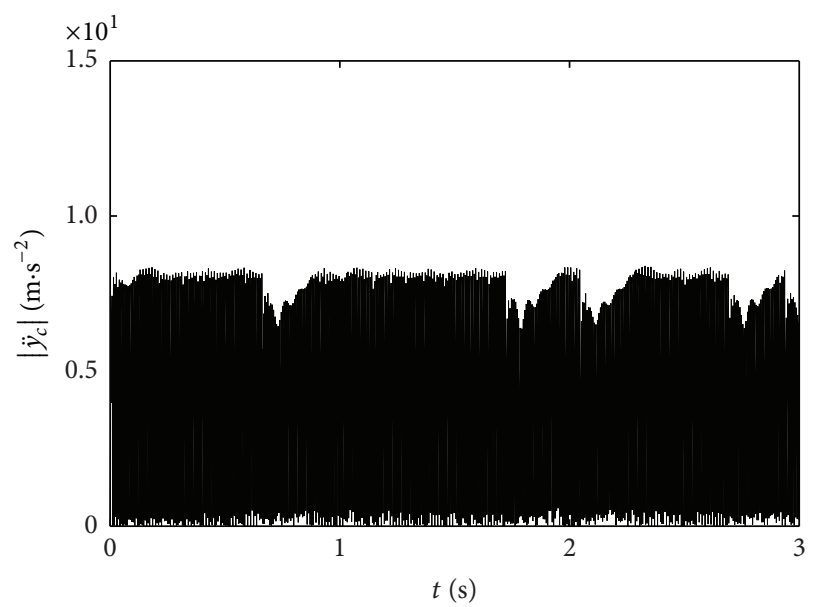

FIGURE 8: System acceleration time history diagrams for $v_{0}=15 \mathrm{RPM}$ and $F=500 \mathrm{~N}$.

speed. The vibrations for all the DOFs of the system can be attenuated and stabilized, with the trajectory rotating inward and gradually converging on the focus of the phase plots in Figure 5, when the brake pressure was not sufficiently high. However, the stabilities of both linings and the caliper along the $y$-axis were lost when the brake pressure increased to the stability threshold for a given speed. Figure 6 shows that their acceleration increased to a certain value. Meanwhile, the trajectory rotates outward, and limit cycles were formed in Figure 7. Thus, the phase plots were consistent with the system stability characteristics determined by calculating the system eigenvalues.

The system stability transition at a given speed was directly related to the negative slope of the Stribeck friction effect, which caused the friction coefficient to decrease with the increasing relative speed. Consequently, in contrary to the 

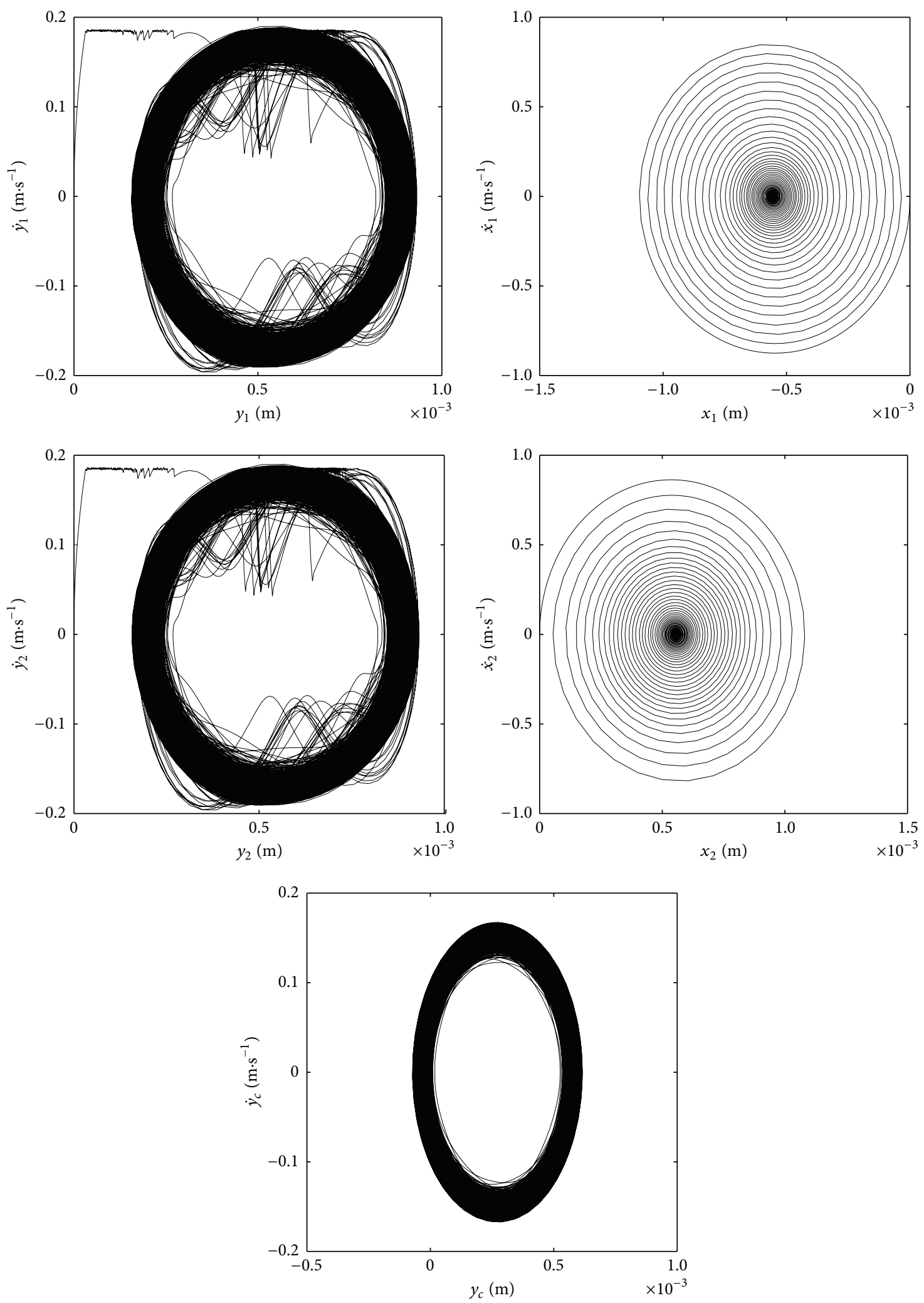

FIGURE 9: System phase plots for $v_{0}=15 \mathrm{RPM}$ and $F=500 \mathrm{~N}$. 


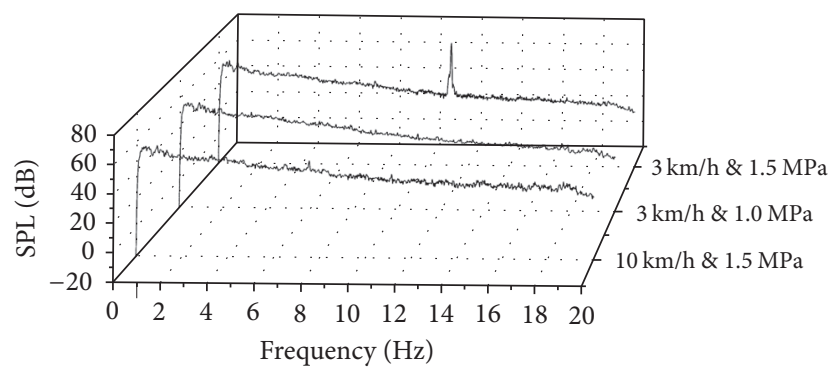

FIGURE 10: Brake noise under different dragging conditions.

case of the viscous damping, the equivalent damping caused by the velocity feedback was negative, with the negative equivalent damping effect becoming more significant with the increasing brake pressure because the friction force was directly proportional to the normal force. Finally, the stability of the system was lost, and a self-excited vibration was induced when the total damping of the system was negative.

Figures 4, 5, 8, and 9 show the effect of the disc rotational speed on the system vibration for a given brake pressure. The stability of the vibration system was lost at a certain brake pressure with the decreasing disc rotational speed. This observation was related to the trend of the friction coefficient versus the speed curve. According to (4), the Stribeck friction model curve was actually a transformed exponential curve (Figure 3). The slope of the curve decreased with the decreasing disc rotational speed. Hence, the negative equivalent damping caused by the velocity feedback decreased as the speed decreased, thereby consequently decreasing the total damping, with the system becoming unstable when the total damping is negative.

\section{Dynamometer Tests}

The abovementioned assertion that the stability of a fixedcaliper brake system decreases with an increasing brake pressure and a decreasing disc rotational speed was based on a numerical investigation using a vibration model. An appropriate fixed-caliper disc brake was used to conduct a dynamometer test using the standard SAE J2521 test procedure and validate the numerical findings.

The test data presented in Figure 10 were obtained from three stops along the corresponding drag cycles using the same initial brake temperature condition, as prescribed in Section 3, Module 4 of SAE J2521. A brake squeal with a frequency of $11,100 \mathrm{~Hz}$ and a sound pressure level (SPL) of $83 \mathrm{~dB}$ was observed at a drag speed of $3 \mathrm{~km} / \mathrm{h}$ and a brake pressure of $1.5 \mathrm{MPa}$. However, no squeal was observed, and the maximum sound pressure level was $57 \mathrm{~dB}$ when the brake pressure was decreased to $1.0 \mathrm{MPa}$, or the drag speed was increased to $10 \mathrm{~km} / \mathrm{h}$. This finding indicated that the probability of brake noise generation decreased with the decreasing brake pressure and the increasing brake speed. Figure 11 shows the SPL data for all the stops prescribed in Section 3, Module 4 of SAE J2521, which substantiates the abovementioned observations on the brake noise occurrence.

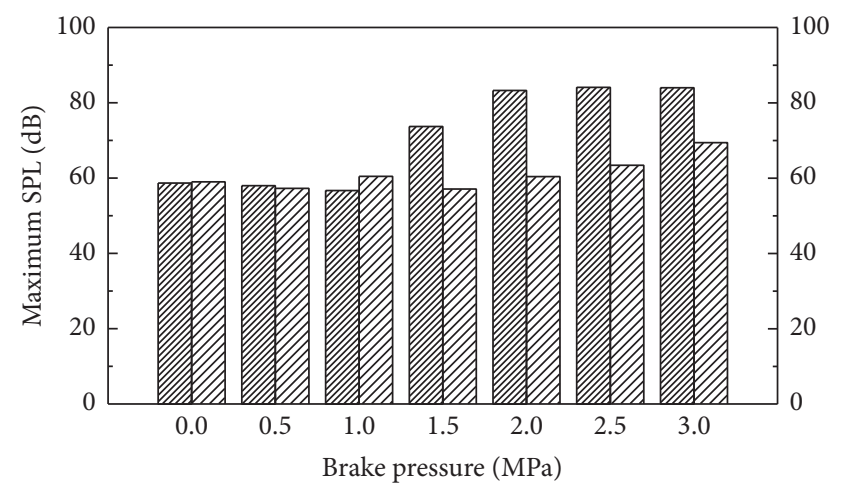

\section{$3 \mathrm{~km} / \mathrm{h}$} WIIt $10 \mathrm{~km} / \mathrm{h}$

FIGURE 11: Maximum SPL data obtained as prescribed in Section 3, Module 4 of SAE J2521.

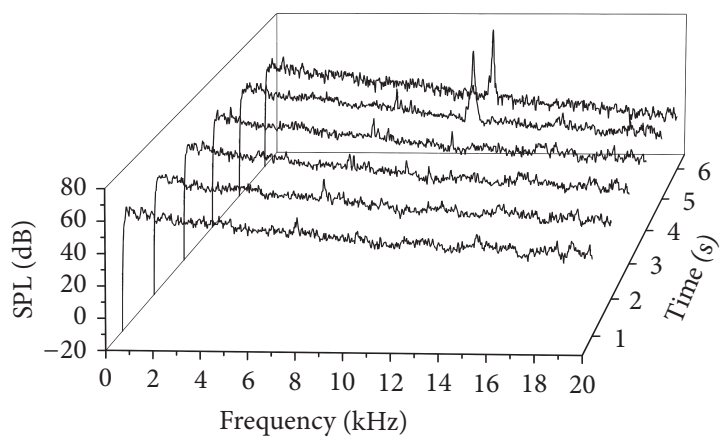

FIGURE 12: Brake noise during the deceleration braking process.

The effects of the disc rotational speed on the brake noise were not only investigated in the drag section of the dynamometer test, but also in the deceleration section. Figure 12 shows the complete brake noise spectrum for the ninth stop prescribed in Section 7, Module 7 of SAE J2521. The disc was forced-braked from $50 \mathrm{~km} / \mathrm{h}$ to rest under a brake pressure of $2 \mathrm{MPa}$ at this stop. The figure showed no noise at the beginning of the braking process. However, the brake noise with an $11,000 \mathrm{~Hz}$ frequency was generated in the final stage of the process as the rotation speed of the disc decreased with time.

\section{Conclusion}

This study developed a 7-DOF vibration model of a fixedcaliper disc brake based on the Stribeck effect. The eigenvalues of the corresponding Jacobian matrix were calculated to analyze the system stability. Furthermore, the acceleration time history diagrams and the phase plots of each DOF in the vibration system were obtained by solving the system equations, revealing regular relationships among the brake pressure, disc rotational speed, and generated noise. The dynamometer tests were used to determine the system parameters and verify the numerical analysis results. The main conclusions drawn from the findings of the study are as follows: 
(1) The probability of brake noise generation increases with the increasing brake pressure because the velocity feedback causes a negative equivalent damping, which increases with the increasing brake pressure.

(2) The probability of brake noise generation increases with the decreasing disc rotational speed because the slope of the curve decreases with the decreasing disc rotational speed, and the negative equivalent damping caused by the velocity feedback decreases as the speed decreases, which also decreases the total system damping.

(3) The 7-DOF brake vibration model based on the Stribeck effect can be used to design and investigate the brake system parameters because its brake noise predictions agree well with the dynamometer test results.

\section{Conflicts of Interest}

The authors declare that there are no conflicts of interest regarding the publication of this paper.

\section{References}

[1] P. Liu, H. Zheng, C. Cai et al., "Analysis of disc brake squeal using the complex eigenvalue method," Applied Acoustics, vol. 68, no. 6, pp. 603-615, 2007.

[2] J. G. P. da Silva, E. R. Fulco, P. E. D. Varante, V. Do Nascimento, F. N. Diesel, and D. L. Boniatti, "Numerical and experimental evaluation of brake squeal," SAE Technical Papers 2013-360030, 2013.

[3] A. Belhocine and N. M. Ghazaly, "Effects of material properties on generation of brake squeal noise using finite element method," Latin American Journal of Solids and Structures, vol. 12, no. 8, pp. 1432-1447, 2015.

[4] A. Papinniemi, J. C. S. Lai, J. Zhao, and L. Loader, "Brake squeal: a literature review," Applied Acoustics, vol. 63, no. 4, pp. 391-400, 2002.

[5] L. T. Matozo, A. Tamagna, H. A. Al-Qureshi, A. R. Menetrier, and P. E. Varante, "Investigation of the relation between friction material abrasive properties and the squeal noise tendency in automotive disc brake systems," International Journal of Acoustics and Vibrations, vol. 17, no. 4, pp. 200-203, 2012.

[6] S.-K. Yang, Z. Sun, Y.-J. Liu, B.-W. Lu, T. Liu, and H.-S. Hou, "Automotive brake squeal simulation and optimization," SAE Technical Paper 2016-01-1298, 2016.

[7] F. Chen, "Disc brake squeal: an overview," SAE Technical Papers 2007-01-0587, 2007.

[8] J. Kang, "Finite element modeling for stick-slip pattern of squeal modes in disc brake," Journal of Mechanical Science and Technology, vol. 28, no. 10, pp. 4021-4026, 2014.

[9] S. Hegde and B.-S. Suresh, "Study of friction induced stickslip phenomenon in a minimal disc brake model," Journal of Mechanical Engineering and Automation, vol. 5, pp. 100-106, 2015.

[10] C.-Y. Teoh and Z.-M. Ripin, “Transient analysis of drum brake squeal with binary flutter and negative friction-velocity instability mechanisms," Journal of Vibroengineering, vol. 13, no. 2, pp. 275-287, 2011.
[11] T. Nakae, T. Ryu, A. Sueoka, Y. Nakano, and T. Inoue, "Squeal and chatter phenomena generated in a mountain bike disc brake," Journal of Sound and Vibration, vol. 330, no. 10, pp. 21382149, 2011.

[12] A. R. AbuBakar and H. Ouyang, "A prediction methodology of disk brake squeal using complex eigenvalue analysis," International Journal of Vehicle Design, vol. 46, no. 4, pp. 416-435, 2008.

[13] N.-P. Hoffmann and L. Gaul, "Friction induced vibrations of brakes: research fields and activities," SAE Technical Papers 2008-01-2579, 2008.

[14] N. M. Kinkaid, O. M. O’Reilly, and P. Papadopoulos, "Automotive disc brake squeal," Journal of Sound and Vibration, vol. 267, no. 1, pp. 105-166, 2003.

[15] F. Chen, M.-K. Abdelhamid, P. Blaschke, and J. Swayze, "On automotive disc brake squeal part III test and evaluation," SAE Technical Papers 2003-01-1622, 2003.

[16] K. Shin, M. J. Brennan, J.-E. Oh, and C. J. Harris, "Analysis of disc brake noise using a two-degree-of-freedom model," Journal of Sound and Vibration, vol. 254, no. 5, pp. 837-848, 2002.

[17] F.-H. Yang, W. Zhang, and J. Wang, "Sliding bifurcations and chaos induced by dry friction in a braking system," Chaos, Solitons \& Fractals, vol. 40, no. 3, pp. 1060-1075, 2009.

[18] M. Paliwal, A. Mahajan, J. Don, T. Chu, and P. Filip, "Noise and vibration analysis of a disc-brake system using a stick-slip friction model involving coupling stiffness," Journal of Sound and Vibration, vol. 282, no. 3-5, pp. 1273-1284, 2005.

[19] N.-M. Kinkaid, O.-M. OReilly, and P. Papadopoulos, "On the transient dynamics of a multi-degree-of-freedom friction oscillator: a new mechanism for disc brake noise," Journal of sound and vibration, vol. 287, no. 4, pp. 901-917, 2005.

[20] I. Ahmed, "Analysis of ventilated disc brake squeal using a 10 dof model," SAE Technical Papers 2012-01-1827, 2012.

[21] H. Wang, X. Liu, Y. Shan, and T. He, "Nonlinear behavior evolution and squeal analysis of disc brake based on different friction models," Journal of Vibroengineering, vol. 16, no. 5, pp. 2593-2609, 2014.

[22] R. Stribeck, "The key qualities of sliding and roller bearings," Zeitschrift des Vereines Seutscher Ingenieure, vol. 46, no. 38, pp. 1342-1348, 1902.

[23] L.-C. Bo and D. Pavelescu, "The friction-speed relation and its influence on the critical velocity of stick-slip motion," Wear, vol. 82, no. 3, pp. 277-289, 1982.

[24] A. Tustin, "The effects of backlash and of speed-dependent friction on the stability of closed-cycle control systems," Journal of the Institution of Electrical Engineers-Part IIA: Automatic Regulators and Servo Mechanisms, vol. 94, no. 1, pp. 143-151, 1947.

[25] B. Armstrong-Hélouvry, "Stick-slip arising from Stribeck friction," in Proceedings of the IEEE International Conference on Robotics and Automation, pp. 1377-1382, IEEE, Cincinnati, Ohio, USA, May 1990. 


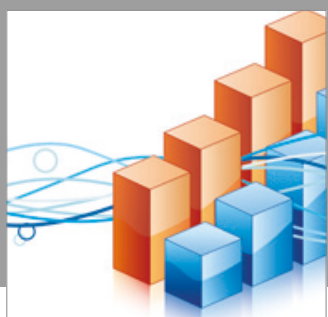

Advances in

Operations Research

vatersals

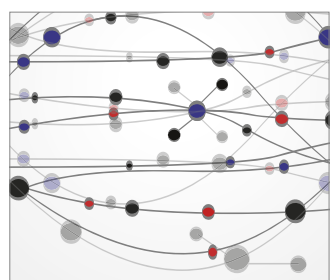

\section{The Scientific} World Journal
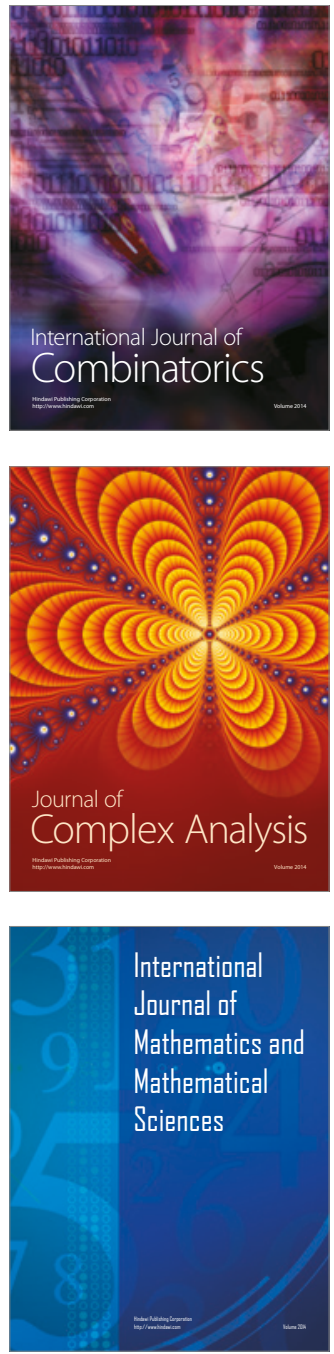
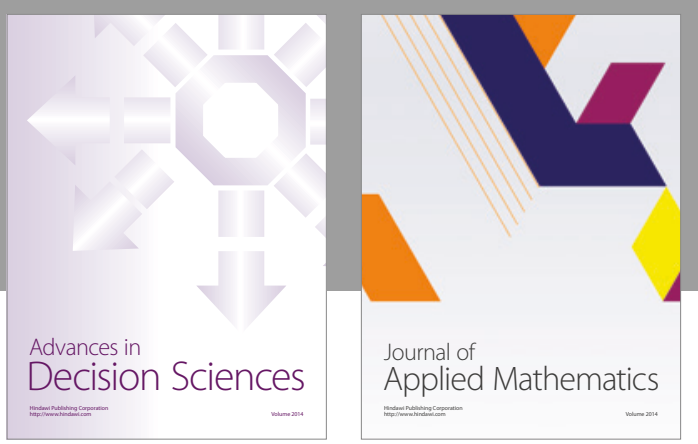

Algebra

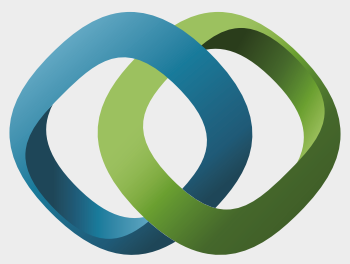

\section{Hindawi}

Submit your manuscripts at

https://www.hindawi.com
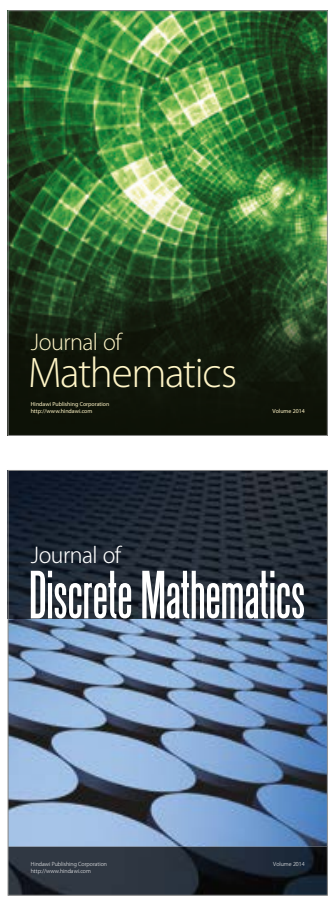

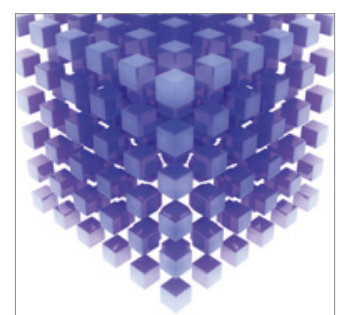

Mathematical Problems in Engineering
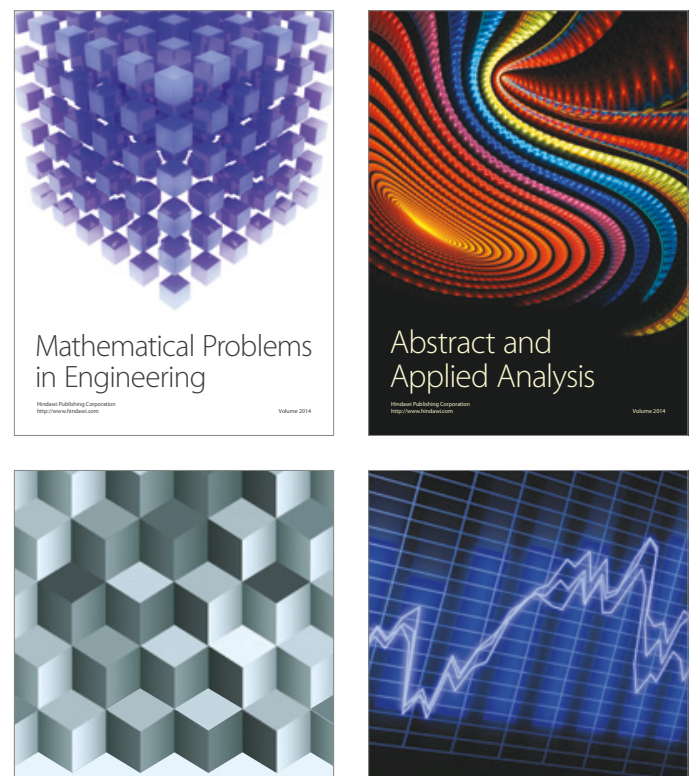

Journal of

Function Spaces

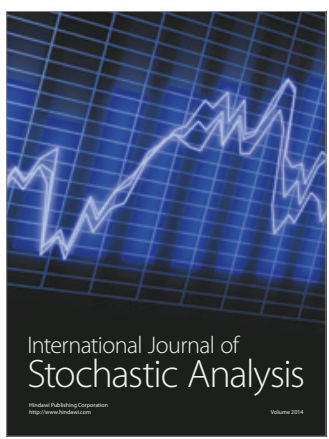

Probability and Statistics
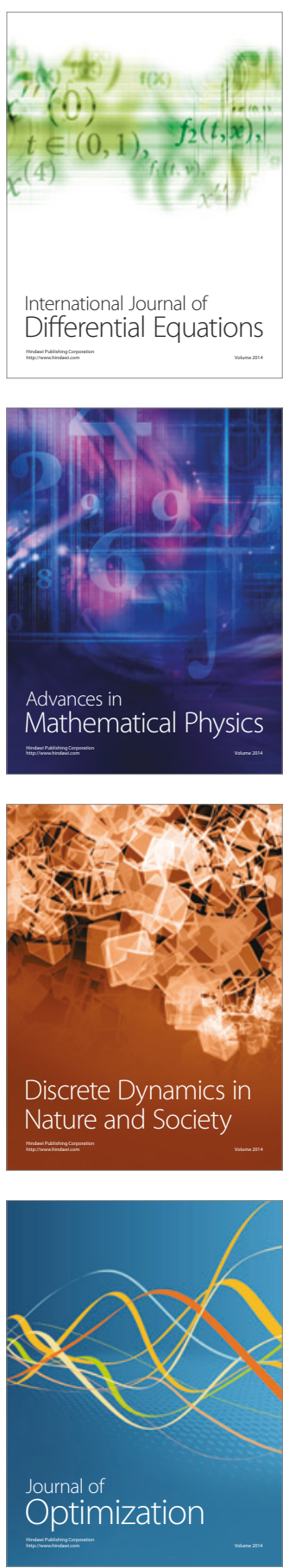